\title{
LSP and Interlanguage: Some Empirical Studies
}

\author{
Larry Selinker and Dan Douglas
}

\begin{abstract}
LSP and interlanguage studies in SLA need each other. A series of questions which should be open to empirical investigation are then presented. Some possible interrelations of LSP and II are discussed. Finally, some of the questions are explored in terms of the empirical studies which appear in this issue of the Journal.
\end{abstract}

\section{Introduction}

It is with great pleasure that we accepted an invitation from the editors of this Journal to coedit a special issue on the general topic of the relationship between interlanguage (IL) studies in second language acquisition (SLA) and language for specific purposes (LSP). ${ }^{1}$ We have felt for some time that both areas, which have developed independently, need each other and to date have by and large ignored each other. We feel that the lack is mutual and that this situation is unfortunate.

From the LSP side, Widdowson (1983) has argued strongly that there is "no coherent theory of LSP" and that important decisions affecting learners are regularly being made on unprincipled grounds. In Selinker (1986) it is argued that LSP will continue to lack that theory until it carefully integrates into its pedagogical concerns, the IL talk and writing that our students produce in abundance in our classes. LSP teachers are quite aware in a general way that fossilization and language transfer effects are exhibited in our students, but too often appear unwilling or unable to integrate the insights achieved in SLA studies into their LSP pedagogical concerns in a principled way. In Selinker (1986) these issues are discussed, especially in terms of the advantages that come about for learners in creating fossilized ILs and the advantages to teachers of "teaching round" fossilization in terms of discourse domains in IL.

From the II side, one important aspect of SLA research which is of high topical relevance is the relationship between context and II use, development and fossilization. In the current literature this relationship is handled in several distinct ways. A background point, as has been argued elsewhere (Selinker, 1984), is that we in SLA have done poorly in integrating context with II. In the

\footnotetext{
Addresses for correspondence: Larry Selinker, ELI, University of Michigan, Ann Arbor, MI 48109, USA; Dan Douglas, English Department, Jowa State University, Ame, IA 50010, USA.

'We use LSP and not ESP for a host of reasons. The most important one is that we feel that those of us who teach English for specific purposes should not cut ourselves off trom what is happening in the rest of the language for specific purposes world We hope that what appeas tere reinforces that view. One point that Swales (PC) has made is that unlike most other disciplines, LSP is a worldwide one, this means of course that the best papers could as well be written in Singapore as in Seatter Lae as in Los Angeles. Noce the countries covered by the authors represented here. ard (USA). Barkho (Iraq). Brigts (USA). Cornu \& Delahaye (Belgium), Michaeu \& Bilimyer (USA), St. John (Spain \& UK), Skelion \& Pindj (Zaire \& UK), Ulijn \& Strother (Holland \& USA). We further hope that the bringing together of LSP \& IL will help continue the internationalization of authors represented in our protessional journals.
} 
U.S. at any rate, we have been preoccupied in SLA with bits of IL learning and/or with tasks divorced from clear everyday contexts, that is, with tasks divorced from contexts which are important to the "real-life" needs and interests of learners. Current approaches to SLA in general have found themselves in the position of having to examine "relationships" and "interactions" of artificially separate components after the research results are in (see Davies et al., 1984, passim).

LSP and IL studies, in our experience, often look at the same data and do (or, at least, should do) similar things. Take, for example, the study of learner strategies; both fields have looked at this phenomenon and often talk about it in similar terms, but hardly refer to each other's work. Once again, we feel that the lack is mutual. At present, the situation is that IL studies in SLA and LSP studies hardly know each other and we hope that this special issue of ESPJ will help ameliorate this situation and provide beneficial long term mutual interaction.

\section{Research Areas and Specific Questions}

In our call for papers, we intended this special issue to focus on two research areas:

1. LSP as an important context for the development of IL, that is, "specificpurpose acquisition" as a branch of SLA:

2. The effect of the close integration of IL thinking on LSP teaching, testing, and research concerns.

We were interested in theoretical, empirical, and methodological papers, that is, both empirical studies and position papers. If someone wrote a position paper, we felt it would be helpful for that paper to show in some manner the way to an empirical linking, at least in principle. Teaching methodology papers could, we felt, relate either to variation in learner IL by LSP context or changes in learner IL (i.e. possible acquisition) and non-changes in IL (i.e. possible fossilization) over time in LSP contexts. Namely, a true teaching/learning perspective.

In particular, we were interested in the following types of issues, though this was not intended to be a closed list:

1. In a principled way, how are we to integrate into our LSP thinking the IL talk and writing our studends produce in abundance in LSP classrooms?

2. How does restricted, special purpose language use differ for native speakers and non-native speakers?

3. How might context-specific recognition and reinforcement of some types of incorrect "part-knowledge" aid II learning in LSP contexts? Which types? (This idea particularly is derived from Davies, 1984, xii.)

4. Which IL forms and structures in which LSP contexts are associated with successful LSP learning and which are associated with unsuccessful LSP learning?

5. What would be the shape of pedagogical and/or testing principles that specify Il form and structure by LSP contexts?

6. In which LSP areas might fossilization be beneficial to IL learners, and what aspects of the IL system might we want to try to encourage toward fossilization?

7. What evidence is there that IL/LSP forms, structures, concepts or abilities may transfer from one context to another, that is, "internal-IL" transfer? Is there any evidence that some may not? 
8. Can we identify and teach to our students which IL "safe rules" are essential within particular LSP contexts?

9. What is the relationship of strategic competence to LSP contexts? Are some strategies universal, others context-specific?

10. How do comprehension and noncomprehension of LSP texts affect IL development in LSP contexts?

11. How much variation in IL communicative competence is there? And do certain individuals show more variation than others as they move from one LSP context to another? How much can such variation be related to: (a) background, (b) formal schemata, (c) levels of confidence?

12. How would the use of "subject-specialist informant" procedures affect our understanding of the above issues?

Overall, this special issue attempts to address two types of fundamental questions. The first of these concerns the nature of LSP and the aspects of it that might profitably be integrated into our thinking on IL and SLA. The second considers the question of what qualifies LSP as an independent line of research and pedagogy that may have relevance for IL and SLA studies. Historically, LSP has been a pedagogically oriented discipline that arose, first, from a demand on the part of language-learning consumers in developing nations for teaching that focused on specific technical areas (mainly development-related), and second, from a research interest in register analysis that led naturally to taxonomies of specific content for language teaching. Thus, we saw the publication of numerous texts on such topics as "English for engineers," "scientific French," "business telephone skills," and so on. The emphasis was on "learner needs" related to specific vocational and academic themes and topics (Strevens 1980). However, it has been acknowledged that this approach has been somewhat ad hoc (e.g. Widdowson 1983, p. 13) and largely unrelated to a coherent theory of SLA (by the same token, as we have implied, SLA has been largely irrelevant to specificpurpose concerns). Indeed, it can be seen that the LSP impetus arising from product-oriented needs/register analyses will lead logically to the dead-end of idiosyncracy, defined learner-by-learner, situation-by-situation. How can LSP provide theoretical principles generalizable enough for IL and SLA studies to build on?

Where the generalizability comes from, in our view, is in focusing not so much on the "specific" nature of LSP, but rather more on the "purpose" side of it. This leads us in a couple of directions: (a) toward the analysis of language use in context (Selinker \& Douglas, 1985), and (b) toward the study of "procedures for making sense" (Widdowson 1983, p. 88) within domains of language use which learners will recognize as relevant to their extra-linguistic concerns.

The first direction, toward an understanding of "context" in IL and SLA is of current concern to a theory of LSP. Our perspective, which suggests IL analysis within well-defined, sociofunctionally real and learner-important contexts, was forshadowed by the work of the Council of Europe Modern Languages Projects. Trim $(1984$, p. 20) succinctly states a guiding principle of that effort: “. . . a learning biography consists not of a straight-line progress from elementary to intermediate to advanced, but an accumulation of life-related learning experiences." This philosophy, applied to language learning, effectively integrates LSP and SLA perspectives, in that it leads to studies of IL particularities within experiences of life. Selinker and Douglas (1985) have employed the phrase 
"slices of life" to refer to the internal contexts associated with the construction of ILs. Widdowson (1983, pp. 54-59) presents a cogent discussion of the relationship between context and language use/learning and integrates a number of terms representing various perspectives (plan, script, scenario, frame) into his own elaboration of the term "schema," which may be said to derive from Firth's notion of "context of situation" (Firth, 1957). The interesting question of what constraints this internal context may impose on IL construction is a matter for empirical research.

The second direction that LSP suggests for IL and SLA studies, that of "procedures for making sense," focuses us on negotiation and interaction in IL development. As Widdowson (1983) points out, language use/learning calls for more than the simple projection of domains/schemata, because language use involves audiences and interlocutors, and hence, often requires modification of the internal context. Once again, we are indebted to Widdowson (1983, pp. $67-79$ ) for a discussion of procedural activity, which he analyzes into "frame procedures" (which establish and maintain propositional frames of reference), "routine procedures" (for realizing the illocutionary value of linguistic interactions) and "formulation procedures" (for recapitulating propositional content and illocutionary intent). It is this notion of procedural activity which offers the possibility of generalizing from the particularities of LSP domains. Widdowson is concerned with finding a set of general principles for establishing LSP as a legitimate discipline within language pedagogy. We suggest that the study of procedural activity also can provide us with a link between LSP and SLA studies: procedures can be seen as the means by which second language knowledge is modified within domains of experience. This, too, is a matter for empirical research. The research agenda is one that will of necessity be informed by work in a number of areas and shared by LSP and IL and SLA jointly.

We want to suggest that both fields need a certain kind of openness: an openness to details of IL particularities in context. We want to suggest an openness to detailed descriptions of "IL in its own terms." We know so little about IL particularities in a wide variety of contexts, especially about ILs that are not Engish-based. If we need universals at all, we need an openness to particular kinds of universals, namely IL universals.

As hinted above, we want to further suggest an alternative and larger framework which locates IL analysis in contexts which meet two criteria: (a) that they are well-defined, and (b) that they are sociofunctionally real and important to the learners under study. It has been argued elsewhere (Selinker, 1984) that LSP presents a series of contexts that meet these criteria. These contexts are reasonably well-defined since there exists macro-level descriptive work which has been done by colleagues in the following overlapping fields: ethnography, ethnomethodology, the sociology of science, the sociology of knowledge, and cross-cultural pragmatics.

\section{Empirical Studies}

What have we found out from the empirical studies contained in this special issue? We have space for only a few major points. 
First, several studies have compared native (N) and non-native (NN) behavior in a SP context: Briggs, Micheau, and Billmyer; Ulijn and Strother (all this volume), after reviewing genre and discourse analysis results of professional scientific and technical (ST) research, ask if L2 students in ST contexts opt for ST syntax in their IL-writing. They compared Dutch L2 students in English with American L1 student English writers in computer science and humanities, matched evenly. Both groups wrote on a computer science topic. Technical students preferred EST syntax more than humanities students, as might be expected, but L1 writers did not use ST register features more than L2 writers, regardless of knowledge of subject matter. The conclusion of the authors is that Dutch L2 writers make greater effort to find contextual support in creating IL because of their limited English; that is, they used their registral knowledge to shape their IL product more than the NSs. Seemingly, this is because they do not have paraphrase skills and are groomed to write in "standard" ST style. This may prove to be one of the causes of fossilization in a LSP context.

Ulijn \& Strother then make the important pedagogical point that we may not need to teach certain ST structures to some students in some circumstances. Given the fact that these learners read so much ST English, salient features of ST discourse such as the passive and nominalization, may not need priority in EST teaching. Another way to look at this is to suppose that these syntactic features might be unmarked for ST discourse (Givon, 1977, section 2.3 for a discussion of discourse markedness) and thus may be easily transferred from one $\mathrm{NN}$ context to another (i.e., internal-IL transfer) - in this case from technical reading to IL technical writing. This is surely an area worthy of future exploration.

Briggs explores the context of IL use, comparing NSs and NNSs in a graduate architecture course. As part of the course, six professors served as jurors for a role-playing situation where students presented their designs of an office or apartment building, a task analogous to the real-world task of selling designs to clients. Jurors considered the Il of over half of the NNSs to be such that they could not perform well in a job which involved communicating with clients in local architecture firms. This judgemental result contrasted with the fact that the NNSs did as well in the course in terms of grades as native speakers. It may turn out that grades in this situation have little to do with talk and much to do with graphic ability and with written IL, where the NNSs have time to revise their Il toward precision. How is it that professors in this situation complain about their students IL and still, at the same time, give them good grades? There seems to be a conflict, which may be more widespread than hitherto believed, between judging students as students versus judging them as potential colleagues; in other words, a conflict between academic success and discourse success. Briggs (this volume) also presents information on the interactional differences between talk in different activity types (studio vs. juried presentations) in the same domain of talk: work talk. In the studio, NNSs can use context to compensate for lack of precision in the IL, whereas in the presentation this cannot be done, thus apparently having to produce a more comprehensible IL in that context.

Briggs mentions fossilization as something that needs to be studied in connection with her results. She explores how ILs are judged in terms of their effectiveness for particular tasks in architecture. It may be that the LSP context here is 
contributing to fossilization of a learner's strategic competence. In one task, there exist more than talk strategies for getting the student's message across, for example, the student can pick up a pen and draw. This might contribute to context-bound fossilization in that the instructor, in a seemingly "interactive" situation, has appeared to give up on talk as he walks around the class, whereas in the other situation, NNSs still seem to need to strive for precision and appear to be developing IL in that context. This fits in with the view that learners may be fossilizing at the point of the achievement of communicative needs (as measured by good grades), but what we have here is possibility that this phenomenon may be more context-bound than previously reported in the literature.

Ard discusses why SLA theory, as formulated, has trouble accounting for the variable acquisition of foreign teaching assistants (FTA's) in terms of "comprehensible input", "negotiated input," and "comprehensible output," three concepts important to current SLA theorizing. His point is that if SLA theory is general, then it should cover FTA acquisition. However, none of these accounts of SLA distinguishes between what successful FTA's have done in "real-life" language tasks and what less successful FTA's have and have not done, that is "the particularities of how FTAs acquire and fail to acquire the language abilities necessary for success in their jobs." Ard points out that there has been little research in SLA into the intricacies of changes in discursive abilities. He brings to the fore the psychological variable of attention, namely, attending to the relevant properties of classroom language use and academic office language use. Ard distinguishes predispositional attention, where one attends to what he calls "the basic facts" of language, and another type of attention where it is open to question whether there is an equal predisposition to attend to other aspects of language use - aspects that may be crucial to FTA success. The interesting testable claim here is that all participants in a content class will automatically attend to certain facets of discourse, but will have a predisposition to fail to attend to others.

Variation in IL writing is jllustrated in the research note by Barkho (1987) on the Arabic-English IL of university students in Iraq. The written IL of these students appears to vary according to the academic context that they find themselves in. There is a hierarchy here related to "school leaving" exams. Economics students have the most basic ILs: the geology students show somewhat greater control of both subject matter and English writing. Engineering students are on a higher level: sentence-connectors appear for the first time, as does coherent paragraphing. The best writers are the medical students who employ some sophisticated linguistic devices such as variation in topic reference. Thus, in this LSP context, there seems to be a correlation between general exam scores, subject matter, and IL form. Barkho discusses the practical consequences for LSP course design, suggesting that traditional EAP concepts will be of varying value for his institution.

An interesting group of papers in this Special Issue are those by St. John, Skelton \& Pindi, and Ulijn \& Strother. We see in these three papers, a number of phenomena that have not been reported in the SLA literature. In particular, the papers highlight certain perceptual variables that relate to the formation of ILs in three contexts: (a) Spanish professionals creating written ILs in English, (b) 
Dutch technical students creating written ILs in English, and (c) Zairean university students creating written ILs in English and French. The Spanish professionals who have to publish in English may have a view of English as "a baby language," not a beautiful, elegant, and complex language that academic Spanish has to be. In fact, one of the subjects actually said that "English is for bobos." So, for at least some of the Spanish scientists, their IL composing strategies go something like this: they first write in a "baby Spanish," then they translate that into English, and then they revise for coherence and cohesion. However, it is even more complicated than that. The IL composing strategies seem to vary according to the section of the technical text the $\mathrm{NN}$ is composing. For example, "procedures" sections may involve memorized formulaic language and the NN writer may start directly in English. For those cases and for those NN writers in this sitation who compose directly in English, the composing processes may not be recursive, but may be linear. That is, "revision" does not concern content, but only minor spelling and grammatical points.

The Ulijn Strother paper (described above), in a comparison of NS and NNS computer science students in the U.S. and Holland, shows that Dutch - English IL of the Dutch computer science students is closer to the perceived stereotypic highly technical style than is the technical English of the NSs.

The Skelton \& Pindi study examines the writing of Zairean university students in a multilingual setting, where each student knows at least four languages: a vernacular, a lingua-Franca, French, and English. The latter two are for use in the academic culture only, but it appears that perceptually "writing in a European language is writing in a European language." At certain key points, the students do not seem to distinguish between French and English, using French and English terms almost interchangeably. Thus, this study shows what a study of IL-particularities in generally unknown LSP contexts can do for us. It can highlight variables not normally conceived of by SLA researchers; in this case learners seeing two quite distinct TLs as the same and transferring "freely" from one to the other. We note that without this information we would be faced with some unexplainable transfers from L3 to L4. Another thing shown in this data is that an "overreaching" of the resources of an IL can be brought about when the task involves the expression of complex and subtle technical thoughts in an LSP contest.

These three case studies provide some off beat phenomena not usually discussed in SLA research, but which may be important to the formation of IL and not only in SP contexts. Interestingly, the perceptual aspect of the formation of ILs shown in the three papers appears to coincide with some recent work in perceptual dialectology, where coping strategies affect the productive shape of English dialects (Preston, in press). Here we see a parallel to the productive shapes of written ILs. What we do not have data on is the oral technical ILs, which are affected (we hypothesize) in the "talk about work" domain by some similar perceptual mechanisms. Perception/production problems are an old concern in language teaching and we may be reaching a new type of understanding here.

Cornu \& Delahaye present a microanalysis of Flemish-French IL across several contexts, talk about work (economics) being one of them. In terms of IL 
particularities, the work-related IL talk of one subject is strikingly different from more ordinary, everyday life story topics. In the work talk, the IL syntax is fairly target like, but when relating life story information, there are many IL-particular forms. When the talk is about work, language production is fluent, and from a rhetorical point of view, the information is well-structured, explicit connectives are used, and lexical items are targetlike (Selinker \& Douglas, 1985). Here there are also no comprehension problems. In the life story domain, on the other hand, there is lack of understanding of many NS questions. There are many hesitations and gropings for vocabulary, with NL, Flemish words being substituted for French in some cases. This study was repeated with the same learner six months later and once again there were large variations in the two domains. The authors, importantly, dismiss background knowledge as a relevant variable, since presumably first-person life-story information is as well-known to the speaker as technical information. They look at lexis and hypothesize that the "degree of integration of the target lexical system" in the IL is a key variable in determining learner IL and that this will vary by context.

Finally, not all studies produced results that would add complications to current SLA thought and this is important to know as well. Micheau \& Billmyer use videotapes to look at oral ESL NN/NN interaction (including a range of NLs) at an advanced level, comparing it to $\mathrm{N} / \mathrm{N}$ interaction in an MBA context. They look at such things as competition for turns, opportunities to get the floor, violations in turn-taking, and responding and not responding to "nominations" to get the floor. They have found some differences in this context that colleagues in LSP might not know about, but the differences confirm the SLA lore: unlike NSs, NNSs do not know how to get the floor; they produce inappropriate frames for introducing topics; there are differences in timing and pauses; NNSs do not know that they need fillers to hold the floor. The authors additionally provide a useful range of research questions and have initiated a longitudinal aspect to their work. They report that, in a practical sense, their IL findings compared with NS findings serve as "an empirical basis" for a special component of an LSP course.

\section{Summary and Future Prospects}

In concluding, to what extent have the studies in this volume provided relevant insights to the questions asked at the beginning of this paper? Also, what new questions have been raised in the carrying out of this project? Each author, in his/her own way has tried to integrate the IL talk and writing of learners in the particular LSP situation under consideration. For example, we may know a little more after the Ulijn and Strother study about what will appear in IL technical writing and may not have to be taught in an LSP context. We also have an interesting critique, based on IL texts, of traditional concepts of LSP teaching (Barkho, this volume). Barkho also hints at important IL variation related to subject matter learning.

Some work has looked at $\mathrm{N}$ and $\mathrm{NN}$ speaker differences; primarily Ulijn and Strother; Briggs; and Micheau and Billmyer as described above. The question of LSP contexts possibly "grooming" learners toward fossilization comes to mind in consideration of the Ulijn and Strother and Briggs papers as discussed 
above. However, the question of whether or not fossilized IL systems are at times positive in promoting SLA in LSP contexts has not yet been addressed. We have seen the possibility of internal-IL transfer in the Ulijn and Strother and the Cornu and Delahaye studies. The latter shows us interesting internal-IL differences by domain, where background knowledge appears not to affect IL performance differentially. LSP researchers should investigate the relationships between various types of background knowledge and IL development and fossilization.

The major new area of inquiry that has been raised in this issue is that it is not so much what learners are doing that can affect the development of IL, in these LSP contexts at least, but their perception of the audience. If, in the LSP practical situation, one believes one is "writing for Bobos" (St. John, this volume), then one may write in that way, or if one believes that there is no significant difference between English and French (Skelton \& Pindi, this volume), then one, perhaps, will not hesitate to code switch and mix a French IL with an English IL. Finally, as in the FTA case (Ard, this volume), a failure to attend to certain aspects of language as a learner may affect one's IL as a teacher.

Those colleagues in LSP who wish to look at the SLA literature for help in determining what learning is about should know that current SLA theories might be biased against the LSP case in a crucial way. IL research in SLA has focused almost exclusively on the formation of ILs from an oral point of view, whereas written ILs have been given short shrift. LSP concerns, on the other hand, have been largely on the development of reading and writing competence in L2. It turns out that we know nothing about how the early learning of IL from written texts effects the later-on development of oral ILs, and this is the situation of numbers of university-bound ESL learners in the U.S. and U.K. These learners, it turns out, quite often have been typical subjects in SLA research. So, reflecting upon LSP and IL, we note a potentially vitiating variable inherent in much of current SLA work. However, there is a wealth of LSP-thick description that could help us here, some of which we find in this volume.

In the final analysis, we want to be in the position taken in the original II paper (Selinker, 1972). We do not want our SLA theories to become irrelevant to the way people actually learn second languages. For this not to happen, we have to recognize and investigate the wide range of situational variables that influence the contexts in which ILs are actually being constructed, a good many of them being LSP contexts.

Finally, regarding both a central LSP and IL concern, the St. John and Ulijn \& Strother papers are also about the relationship between genre conventions and IL learning. If it is true that, for example, there exists a universal set of $S$ \& $T$ conventions in input texts to LSP leamers, then one must come to grips with the possibility of "contextual markedness" in II. It has long been a concern, at least in the folklore, as to how much of learning a language in a SP context is language learning and how much is subject-matter learning. It may be the case that some IL forms are marked and some are less marked with regard to LSP contexts and to acquisition (and fossilization) in SP contexts. This line of thought may help untie a difficult knot, but not without careful NS/NNS comparisons.

In the future, what we hope to see in the literature are papers written from both the IL and the LSP viewpoints. We have worked on this special issue for 
over a year and have learned much. Unfortunately, there was not space here for all worthwhile studies we received. We expect some of these "interlanguage" papers to appear in future issues of ESPJ. One problem we tried to face head on is the problem of potential authors who are doing LSP, but who do not yet have the rhetorical/composing skills to report on the large amount of interesting IL workgoing on in the LSP world. This was also the concern expressed by Crandall, the guest coeditor of special issue volume 3 , number 2 . We hope that some sort of international forum will discuss the important problem of making available to colleagues information buried in particular programs.

Acknowledgements -A preliminary version of this paper was presented at the 1987 "Second Language Research Forum," held at USC. We wish to thank those 50 or so colleagues who came to the "Round Table" after the paper to discuss these matters, as well as Bill Rutherford, John Swales, Hiram Vivanco, and Helmut Zobl. This material was also discussed at public lectures hosted by Temple University, Japan (March, 1987) in Tokyo and Osaka. Public discussion in this forum was also most useful for the preparation of this paper. Gladys Valcourt and Jim Patrie served as important hosts for this feedback.

\section{REFERENCES}

Ard, J. (this volume). The foreign TA problem from an acquisition-theoretic point of view.

Barkho, L. Y. (this volume). Interlanguage across academic contexts.

Briggs, S. (this volume). When course success varies from discourse success.

Cornu, A. M. \& M. Delahaye. (this volume). Variability in interlanguage reconsidered: LSP vs. non-LSP talk.

Davies, A. (1984). Introduction. In Davies, et al. ix - xv.

Davies, A., Criper, C. \& Howatt, A. P. R. (Eds.). (1984). Interlanguage. Edinburgh: Edinburgh University Press.

Firth, J. R. (1957). Papers in Linguistics 1934-1951. Oxford: Oxford University Press.

Givon, T. (1977). On Understanding Grammar. New York: Academic Press.

Micheau, C. \& K. Billmyer. (this volume). Discourse strategies for foreign business students: preliminary research findings.

Preston, D. (in press). The methods of perceptual dialectology. In R. Fasold (Ed.) Proceedings of the 14th NWAV. Amsterdam: John Benjamins.

Selinker, L. (1972). Interlanguage. IRAL, 10, 209-231.

Selinker, L. (1984). The current state of interlanguage studies: an attempted critical summary. In Davies, et al, (Eds.) 332-343.

Selinker, L. (1986). LSP and Interlanguage: Interlanguage and LSP. ESPMENA Bulletin. 22, 1- 13.

Selinker, L. \& Douglas, D., (1985). Wrestling with "context" in interlanguage theory. Applied Linguistics, 6, 190-204.

St. John, M. J. (this volume). Writing processes of Spanish scientists publishing in English. 
Skelton, J. \& M. Pindi. (this volume). Acquiring a new context: Zairean students struggle with the academic mode.

Strevens, P. (1980). Teaching English as an International Language. Oxford: Pergamon.

Trim, J. (1984). Introduction to Across the Threshold. In J. A. van Ek \& J. L. M. Trim (Eds.) Across the Threshold. Oxford: Pergamon.

Ulijn, J. M. \& Strother, J. B. (this volume). Interlanguage and EST writing: some syntactic evidence.

Widdowson, H. G. (1983), Learning Purpose and Language Use. Oxford: Oxford University Press.

Larry Selinker is Professor of Linguistics and former Director of the English Language Institute of the University of Michigan. His research areas are: LSP, SLA, ESL theory and rhetorical/grammatical theory in discourse analysis.

Dan Douglas is Assistant Professor of TESL at Iowa State University. His research areas are: language testing, ESL theory, LSP, and SLA. 